
jul-set 2005.

\title{
Polinização manual em abobrinha: efeitos nas produções de frutos e de sementes
}

\author{
Antonio Ismael Inácio Cardoso \\ ${ }^{1}$ UNESP-FCA, C. Postal 237, 18603-970 Botucatu-SP; E-mail: ismaeldh@ fca.unesp.br
}

\section{RESUMO}

Neste trabalho foi avaliado o efeito da quantidade de pólen, utilizando-se polinização manual na produção e na qualidade de sementes de abobrinha. Flores femininas foram polinizadas manualmente com a metade ou com o dobro da quantidade de pólen presente em uma flor masculina para a obtenção de sementes denominadas de primeiro ciclo. Posteriormente, flores femininas das plantas oriundas dessas sementes foram novamente polinizadas com as mesmas quantidades de pólen empregadas no primeiro ciclo, obtendo-se sementes denominadas de segundo ciclo. As quatro populações obtidas (duas em cada ciclo), além da original (sementes comerciais da cv. Piramoita), constituíram os cinco tratamentos que foram avaliados em delineamento de blocos casualizados com seis repetições de dez plantas. Foram estimados o número de frutos por planta, a produção de sementes (número e massa) por fruto e por planta, o peso de 100 sementes, a germinação e o vigor das sementes obtidas. Foram obtidos maior número de frutos e de sementes por planta no tratamento com utilização do dobro de pólen de uma flor masculina ( $2^{\circ}$ ciclo), superior a utilização de metade do pólen de uma flor masculina no $1^{\circ}$ ciclo. A qualidade fisiológica da semente (germinação e vigor) não foi afetada pelos tratamentos.

Palavras-chave: Cucurbita moschata, flores, qualidade de sementes.

\begin{abstract}
Manual pollination of summer squash: effects on fruit and seed production

The effect of pollen quantity using manual pollination on seed production and the quality of summer squash was evaluated. Female flowers were manually pollinated with a half or twice the pollen quantity of a male flower to get seeds named first cycle. Later, female flowers of plants from these seeds were pollinated again with the same pollen quantity of the first cycle, getting seeds named second cycle. These four "populations" obtained (two in each cycle), besides the original one (commercial seeds of cv. Piramoita), constituted the five treatments evaluated in a randomized block design, with six replications and ten plants/plot. Fruit number per plant, fruit mean weight, seed yield per fruit and per plant, 100 seed weight, seed germination and vigor were estimated. Greater fruit and seed number per plant were obtained with twice pollen quantity ( $2^{\text {nd }}$ cycle) than a half pollen quantity ( $1^{\text {st }}$ cycle). Seed quality (germination and vigor) was not affect by treatments.
\end{abstract}

Keywords: Cucurbita moschata, flowers, seed quality.

(Recebido para publicação em 11 de maio de 2004 e aceito em 7 de abril de 2005)

Q ualidade das sementes é fator primordial na produção de hortaliças. A difusão do uso de híbridos levou os produtores a exigirem alta qualidade da semente, já que seu preço é superior aos das cultivares de polinização aberta.

No caso de cucurbitáceas, a polinização manual é uma alternativa utilizada na produção de sementes de híbridos. Neste caso, tanto o parental masculino quanto a quantidade de pólen podem ser controlados.

Segundo Ávila et al. (1989), as polinizações manual e natural tiveram comportamento similar na obtenção de híbridos de abobrinha, com respeito ao número de frutos por planta; porém, a manual foi inferior na produção de sementes por planta. Schlichting et al. (1987) relataram que o aumento na quantidade de pólen aplicada sobre o estigma elevou o tamanho dos frutos e a quantidade de sementes. Lima et al. (2003) obtiveram relação direta entre a produção de sementes em abobrinha 'Caserta' (C. pepo) e a quantidade de pólen aplicada. Quesada et al. (1996) observaram, em abobrinha, relação direta entre a quantidade de pólen, a velocidade de germinação das sementes obtidas e o vigor das progênies resultantes.

Normalmente, a polinização com maior quantidade de pólen resulta em frutos com maior número de sementes e menor possibilidade de aborto (STEPHENSON et al., 1988). Esse processo de abortamento pode ser considerado um mecanismo pelo qual as plantas podem influenciar a qualidade de suas sementes e progênie (LEE, 1984). Porém, na produção de sementes por polinização manual, normalmente são mantidos, no máximo, dois frutos por planta, e as flores não polinizadas manualmente são eliminadas.

Segundo Hormaza e Herrero (1996), a alternância entre as gerações gametofítica e esporofítica, no ciclo de vida, é um atributo conservado no reino vegetal. A geração gametofítica, geralmente haplóide, desenvolve-se de esporos (gametas) produzidos por meiose e a geração esporofítica, geralmente diplóide, desenvolve-se do zigoto produzido após a fertilização. Entretanto, ao longo da evolução, a geração gametofítica tem sido reduzida, em relação à esporofítica, tanto em tamanho como em período de vida. Nas plantas superiores, a fase esporofítica é a macroscópica e representa o que se denomina de planta. A influência da fase gametofítica sobre a esporofítica tem sido ignorada, sendo considerada como uma fase passiva, atuando somente como um vetor da transmissão do genoma para a fase esporofítica. Segundo Mulcahy (1979), evidências sugerem que o gametófito de plantas superiores é independente e expressa sua informação genética. Portanto, está exposto à 
Tabela 1. Número de frutos por planta $(\mathrm{NrFrPl})$, massa média de fruto (MMF), número (NS/F) e massa (MS/F) de sementes por fruto, número (NS/P) e massa (MS/P) de sementes por planta. São Manuel, FCA/UNESP, 2003.

\begin{tabular}{llllcll}
\hline Tratamentos & NrFrPI & MMF (g) & NS/F & MS/F (g) & NS/P & MS/P (g) \\
\hline Testemunha $^{1}$ & $1,96 \mathrm{ab}^{2}$ & $1309 \mathrm{a}$ & $218 \mathrm{a}$ & $16,53 \mathrm{a}$ & $441 \mathrm{a}$ & $33,47 \mathrm{ab}$ \\
0,5 flor, $1^{\circ}$ ciclo & $1,76 \mathrm{~b}$ & $1222 \mathrm{a}$ & $163 \mathrm{a}$ & $15,25 \mathrm{a}$ & $297 \mathrm{~b}$ & $27,58 \mathrm{~b}$ \\
0,5 flor, $2^{\circ}$ ciclo & $2,11 \mathrm{ab}$ & $1169 \mathrm{a}$ & $184 \mathrm{a}$ & $15,83 \mathrm{a}$ & $393 \mathrm{ab}$ & $33,74 \mathrm{ab}$ \\
2 flores, $1^{\circ}$ ciclo & $2,27 \mathrm{a}$ & $1101 \mathrm{a}$ & $183 \mathrm{a}$ & $14,90 \mathrm{a}$ & $418 \mathrm{ab}$ & $34,21 \mathrm{ab}$ \\
2 flores, $2^{\circ}$ ciclo & $2,45 \mathrm{a}$ & $1174 \mathrm{a}$ & $179 \mathrm{a}$ & $15,85 \mathrm{a}$ & $440 \mathrm{a}$ & $39,70 \mathrm{a}$ \\
\hline C.V. (\%) & $6,5 \%$ & $14,9 \%$ & $9,8 \%$ & $12,6 \%$ & $11,5 \%$ & $18,0 \%$ \\
\hline
\end{tabular}

${ }^{1}$ Cultivar Piramoita (sementes comerciais); ${ }^{2}$ Médias seguidas pela mesma letra, nas colunas, não diferem estatisticamente pelo teste de Tukey a $5 \%$ de probabilidade.

seleção e, como conseqüência, pode influenciar na constituição genética da geração esporofítica resultante. Geralmente, a seleção natural é a única a atuar sobre a geração gametofítica. Entretanto, Mulcahy (1979), Davis et al. (1987) e Hormaza e Herrero (1996) consideram que o melhorista ao utilizar grande quantidade de grãos de pólen estabeleça competição capaz de selecionar, artificialmente, os mais vigorosos. Assim, as sementes originadas tendem a apresentar maior vigor e as plantas resultantes podem apresentar maior potencial produtivo.

Deste modo, uma grande quantidade de pólen depositado sobre o estigma pode ser favorável à produtividade e à qualidade das sementes produzidas. Já, para o melhorista, há a possibilidade de selecionar populações mais vigorosas expondo as flores femininas a uma grande quantidade de pólen, promovendo competição entre os grãos-de-pólen (DAVIS et al., 1987; HORMAZA; HERRERO, 1996). Este trabalho teve como objetivo avaliar o efeito da quantidade de pólen na polinização manual na produção e na qualidade de sementes de abobrinha.

\section{MATERIAL E MÉTODOS}

Foram realizadas polinizações manuais, diretamente sobre o estigma, utilizando a metade e o dobro da quantidade média de pólen existente em uma flor masculina. As sementes obtidas, nos dois casos, foram denominadas de primeiro ciclo. A cultivar Piramoita (Cucurbita moschata) foi utilizada como população original. Esta etapa foi realizada de agosto a dezembro de 2001.
As plantas resultantes das sementes de primeiro ciclo foram submetidas ao mesmo procedimento de polinização utilizando-se flores masculinas coletadas em plantas do próprio tratamento (metade e dobro da quantidade de pólen). As sementes obtidas foram consideradas como oriundas do segundo ciclo de polinização manual. Esta etapa foi realizada de junho a outubro de 2002.

Para a realização das polinizações manuais, os ápices das pétalas das flores masculinas e femininas selecionadas, ainda fechadas, foram amarradas com fio de lã na tarde do dia anterior ao cruzamento. A polinização foi realizada matutinamente, após retirada das pétalas, por contato entre as anteras e os estigmas. Anteras com tamanho e quantidade de pólen abaixo da média foram descartadas; em média, foram obtidos $24 \mathrm{mg}$ de pólen em cada flor. Para obter o tratamento com metade da quantidade de pólen, as anteras foram divididas, bilateralmente, com o auxílio de uma lâmina.

As quatro populações obtidas (duas quantidades de pólen em dois ciclos) foram avaliadas juntamente com a população original (sementes comerciais da cultivar Piramoita), totalizando cinco tratamentos. O delineamento foi em blocos casualizados, com seis repetições de dez plantas. Nesta etapa a polinização foi realizada por abelhas naturalmente encontradas no campo experimental em todos os tratamentos.

A semeadura foi realizada em bandejas de poliestireno expandido de 128 células, com uma semente por célula, em 21/01/2003, e as plântulas obtidas foram transplantadas para canteiros, quando estavam emitindo a segunda folha verdadeira $(05 / 02 / 2003)$, em espaçamento de $2,0 \times 1,5 \mathrm{~m}$.

A adubação constou de 5 litros de esterco de galinha humificado e $200 \mathrm{~g}$ de adubo formulado 4-14-8 por $\mathrm{m}^{2}$ de canteiro. Após o transplante, foram realizadas adubações em cobertura com nitrocálcio a cada 14 dias (5 g/planta/ adubação). A irrigação por aspersão, realizada invariavelmente no período vespertino, procurou evitar interferências na atividade dos insetos polinizadores. Realizou-se controle químico, principalmente, de brocas, mosca branca e oídio.

Os frutos foram colhidos (07 e 14/ 04/2003) com coloração creme, e foram deixados em repouso por três semanas antes da extração das sementes. Após a extração e a secagem, as sementes foram armazenadas em câmara seca $\left(20^{\circ} \mathrm{C}\right.$ e $40 \%$ UR), até a estabilização do teor de água em 8,0\%. Em seguida, foram eliminadas as sementes chochas ou danificadas.

Foram avaliados o número de frutos por planta, a massa média do fruto, a produção (número e massa) de sementes por fruto e por planta, a massa de 100 sementes, a germinação (BRASIL, 1992) e o vigor das sementes (primeira contagem de germinação e velocidade e taxa de emergência das plântulas em substrato comercial Plantmax ${ }^{\hat{a}}$ ).

A taxa de emergência considerou o número de plântulas emersas 15 dias após a semeadura. $\mathrm{O}$ índice de velocidade de emergência (IVE) foi calculado empregando a seguinte equação (MARCOS FILHO et al., 1987):

$\mathrm{IVE}=\mathrm{E} 6 / 6+\mathrm{E} 7 / 7+\mathrm{E} 8 / 8+\ldots+\mathrm{E} 15 /$ 15 ; onde:

E6, E7; E15 = número de plântulas emersas no $6^{\circ ;} 7^{\circ} ; \ldots .15^{\circ}$ dia.

Os valores obtidos foram submetidos à análise de variância, em esquema de blocos casualizados, com as médias comparadas pelo teste de Tukey a $5 \%$ de probabilidade.

\section{RESULTADOS E DISCUSSÃO}

As plantas do tratamento com a metade do pólen ( $1^{\circ}$ ciclo) produziram menor número de frutos maduros que as plantas dos tratamentos onde foram 
utilizados o dobro da quantidade de pólen existente em uma flor $\left(1^{\circ}\right.$ e $2^{\circ}$ ciclos) (Tabela 1). Schlichting et al. (1990) e Quesada et al. (1996) observaram correlação positiva entre a quantidade de pólen e o vigor da progênie resultante. Segundo Davis et al. (1987), há a possibilidade de aumentar o vigor das populações expondo as flores femininas a uma grande quantidade de pólen; descreveram que plantas derivadas de sementes produzidas sob condições de elevada quantidade de pólen, produziram mais flores e frutos e maior quantidade (número e massa) de sementes por planta. Aparentemente, foi o que ocorreu neste experimento, ou seja, o aumento da quantidade de pólen favoreceu a obtenção de plantas com maior número de frutos.

Entretanto, apenas o $1^{\circ}$ ciclo do tratamento com menor quantidade de pólen foi inferior. Considerando-se que as sementes do $1^{\circ}$ ciclo (de ambas as quantidades de pólen) ficaram armazenadas por um ano enquanto que as do $2^{\circ}$ ciclo tinham sido recém extraídas, talvez tenha havido também efeito do armazenamento das sementes. Durante o armazenamento, há redução de vigor, sendo maior esta redução quanto menor for o vigor inicial das sementes armazenadas (CARVALHO; NAKAGAWA, 2000). Sementes obtidas com a utilização do dobro de pólen ( $1^{\circ}$ ciclo) resultaram em plantas com maior número de frutos mesmo após um ano de armazenamento, o que já não ocorreu com as sementes obtidas com menor quantidade de pólen ( $1^{\circ}$ ciclo). Ressalta-se que as sementes da testemunha permaneceram armazenadas por quase dois anos, nas mesmas condições, sem que houvesse perda de potencial produtivo, evidenciando a importância do vigor inicial sobre a deterioração das mesmas no período de armazenamento.

Considerando-se apenas o $1^{\circ}$ ciclo (mesma idade das sementes), as plantas do tratamento com polinização com o dobro de pólen resultaram em 0,51 frutos (Tabela 1) a mais por planta comparado a utilização da metade da quantidade de pólen, ou seja, um aumento de $29 \%$.

A quantidade de pólen utilizada na polinização manual por dois ciclos não afetou a produção (número e massa) de sementes por fruto (Tabela 1). Deve-se

Tabela 2. Massa de 100 sementes (M100Sem), primeira contagem de germinação $\left(1^{\mathrm{a}} \mathrm{C}\right)$, germinação (Germ), taxa de emergência e índice de velocidade de emergência das plântulas (IVE). São Manuel, FCA/UNESP, 2003.

\begin{tabular}{lccccc}
\hline Tratamentos & $\begin{array}{c}\text { M100Sem } \\
\mathbf{( g )}\end{array}$ & $\mathbf{1}_{\mathrm{a}} \mathbf{C}(\mathbf{\%})$ & Germ (\%) & $\begin{array}{c}\text { Emergência } \\
\mathbf{( \% )}\end{array}$ & IVE \\
\hline Testemunha & $7,43 \mathrm{~b}^{2}$ & $74 \mathrm{a}$ & $94 \mathrm{a}$ & $97,2 \mathrm{a}$ & $13,5 \mathrm{a}$ \\
0,5 flor, $1^{\circ}$ ciclo & $9,22 \mathrm{a}$ & $64 \mathrm{a}$ & $93 \mathrm{a}$ & $97,4 \mathrm{a}$ & $13,0 \mathrm{a}$ \\
0,5 flor, $2^{\circ}$ ciclo & $8,50 \mathrm{ab}$ & $72 \mathrm{a}$ & $93 \mathrm{a}$ & $96,8 \mathrm{a}$ & $13,0 \mathrm{a}$ \\
2 flores, $\mathbf{1}^{\circ}$ ciclo & $8,08 \mathrm{ab}$ & $75 \mathrm{a}$ & $88 \mathrm{a}$ & $98,4 \mathrm{a}$ & $13,6 \mathrm{a}$ \\
2 flores, $2^{\circ}$ ciclo & $8,87 \mathrm{ab}$ & $78 \mathrm{a}$ & $96 \mathrm{a}$ & $98,4 \mathrm{a}$ & $13,6 \mathrm{a}$ \\
\hline C.V. $(\%)$ & $10,2 \%$ & $9,3 \%$ & $3,7 \%$ & $1,6 \%$ & $3,1 \%$ \\
\hline
\end{tabular}

${ }^{1}$ Cultivar Piramoita (sementes comerciais); ${ }^{2}$ Médias seguidas pela mesma letra, nas colunas, não diferem estatisticamente pelo teste de Tukey a $5 \%$ de probabilidade.

ressaltar que neste experimento onde os cinco tratamentos foram comparados, todas as polinizações foram naturais, realizadas por insetos polinizadores e, portanto, a quantidade de pólen colocada sobre o estigma de cada flor que gerou um fruto deve ter sido elevada e aproximadamente a mesma. O número máximo de sementes de um fruto é determinado pelo número de óvulos no ovário da flor feminina (NEPI; PACINI, 1993). Deve-se considerar que o fator variável na obtenção dos tratamentos foi a quantidade de pólen, entretanto, o gineceu manteve-se inalterado. Portanto, se os tratamentos não afetaram o número de óvulos (número máximo de sementes) e a quantidade de pólen depositada pelos insetos foi a mesma e, provavelmente, em grande quantidade, o número de sementes por fruto não foi influenciado pelos tratamentos.

Não houve diferença na massa média dos frutos (Tabela 1). Também Girish (1986), citado por Lima (2000), observou que o número de grãos de pólen não afetou a massa de frutos em abobrinha (C. pepo). Ainda em C. pepo, Stephenson et al. (1988) relataram que o tamanho e massa finais do fruto dependem da quantidade de sementes no mesmo. Considerando-se que não foram encontradas diferenças no número de sementes por fruto (Tabela 1), a ausência de diferença entre os tratamentos para a massa média do fruto é compatível com o descrito na literatura.

As plantas do tratamento com a metade da quantidade de pólen $\left(1^{\circ}\right.$ ciclo $)$ produziram menor número de sementes (Tabela 1) que as plantas dos tratamentos onde foi utilizado o dobro da quan- tidade de pólen ( $2^{\circ}$ ciclo) e na população original (cultivar comercial, sempre com polinização natural). Esta diferença deve-se, provavelmente, ao menor número de frutos no tratamento com menor quantidade de pólen ( $1^{\circ}$ ciclo). Se a quantidade de sementes por fruto não diferiu, a produção de sementes por planta vai depender do número de frutos por planta. Quanto maior este número, provavelmente maior o número de sementes por planta. Também Davis et al. (1987) relataram que plantas derivadas de sementes produzidas sob condições de elevada quantidade de pólen, produziram maior quantidade de sementes por planta.

Quanto a massa de 100 sementes, foram obtidas sementes mais pesadas no tratamento com menor quantidade de pólen no $1^{\circ}$ ciclo, comparativamente à população original (Tabela 2). Provavelmente, este resultado está relacionado ao número de sementes por planta. Quanto menor o número de sementes, maior a probabilidade destas receberem mais reservas (matéria seca) da planta e, portanto, apresentarem maior massa. Também Schlichting et al. (1990) obtiveram maior massa por semente quanto menor o número de sementes por planta, comparando diferentes quantidades de pólen na polinização manual.

Com relação aos demais índices de qualidade das sementes (Tabela 2), não se observaram diferenças significativas entre os tratamentos para todos os índices. A germinação (8 dias) sempre esteve acima dos $88 \%$ e a emergência em substrato (15 dias após a semeadura) acima dos $96 \%$, caracterizando sementes de ótima qualidade fisiológica. 
Apesar da diferença na massa de 100 sementes entre dois tratamentos, não houve diferença na qualidade fisiológica. Carvalho e Nakagawa (2000) citam que as sementes de maior tamanho, ou maior densidade, são as que receberam mais reservas (matéria seca) durante o seu desenvolvimento. Portanto possuem embriões bem formados e com maiores quantidades de reservas sendo, potencialmente, as mais vigorosas. Entretanto, destacaram que há trabalhos em que esta relação entre o vigor e o tamanho da semente não é constatada. Neste trabalho também não se confirmou esta relação entre a massa de 100 sementes e vigor, pois, apesar de haver diferença na massa de 100 sementes entre dois tratamentos, não foram obtidas diferenças na germinação ou vigor entre os tratamentos (Tabela 2).

Considerando-se que toda a polinização, quando comparou-se as cinco populações, foi realizada por insetos e que não houve seleção artificial de frutos que chegaram à maturação, provavelmente as plantas abortaram os frutos com menor quantidade e qualidade das sementes. Lee (1984) considera que este processo de abortamento pode ser um mecanismo pelo qual as plantas podem influenciar, de alguma maneira, a qualidade de suas sementes.

Apesar de não afetar a qualidade das sementes das progênies resultantes, concluiu-se que sementes obtidas com polinização manual utilizando-se menor quantidade de pólen e armazenadas por um ano resultaram em plantas com menor número de frutos, comparativamente à utilização de maior quantidade de pólen, com ou sem armazenamento das sementes. A menor quantidade de pólen ( $1^{\circ}$ ciclo) também resultou em plantas com menor número de sementes em comparação à maior quantidade de pólen $\left(2^{\circ}\right.$ ciclo $)$.

\section{AGRADECIMENTOS}

$\mathrm{O}$ autor agradece à FAPESP pela concessão de auxílio à pesquisa (Processo 01/04400-6).

\section{LITERATURA CITADA}

ÁVILA, C.J.; MARTINHO, M.R.; CAMPOS, J.P. Polinização e polinizadores na produção de frutos e sementes híbridas de abóbora (Cucurbita pepo var. melopepo). Anais da Sociedade Entomológica do Brasil, v.18, n.1, p.13-19, 1989. BRASIL. Ministério da Agricultura e Reforma Agrária. Regras para análise de sementes. Brasília: SNAD/CLAV, 1992. 365p.

CARVALHO, N.M.; NAKAGAWA, J. Sementes: ciência, tecnologia e produção. 4ed. Jaboticabal: Funep, 2000. 588p.

DAVIS, L.E.; STEPHENSON, A.G.; WINSOR, J.A. Pollen competition improves performance and reproductive output of the common zucchini squash under field conditions. Journal of the American Society for Horticultural Science, v.112, n.4, p.712-716, 1987.

HORMAZA, J.I.; HERRERO, M. Male gametophytic selection as a plant breeding tool. Scientia Horticulturae, v.65, n.4, p.321-333, 1996.
LEE, T.D. Patterns of fruit maturation: a gametophyte competition hypothesis. American Nature, n.123, p.427-432, 1984.

LIMA, M.S. Espaçamento entre plantas e quantidade de pólen na produção e qualidade de sementes de abobrinha (Cucurbita pepo). 2000. 75 f. Dissertação (Mestrado) - Universidade Estadual Paulista, Botucatu.

LIMA, M.S.; CARDOSO, A.I.I.; VERDIAL, M.F Plant spacing and pollen quantity on yield and quality of squash seeds. Horticultura Brasileira, Brasília, v.21, n.3, p.443-447, 2003.

MARCOS FILHO, J.; CÍCERO, S.M.; SILVA, W.R. Avaliação da qualidade das sementes. Piracicaba: FEALQ, 1987. 230 p.

MULCAHY, D.L. The rise of the angiosperms: a genecological factor. Science, v.206, p.20-23, 1979.

NEPI, M.; PACINI, E. Pollination, pollen viability and pistil receptivity in Cucurbita pepo. Annals of Botany, v.72, p.527-536, 1993

QUESADA, M.; WINSOR, J.A.; STEPHENSON, A.G. Effects of pollen selection on progeny vigor in Cucurbita pepo x C. texana hybrid. Theoretical and Applied Genetics, v.92, n.7, p.885-890, 1996. SCHLICHTING, C.D.; DAVIS, L.E.; STEPHENSON, A.G.; WINSOR, J.A. Pollen competition and offspring variance. Evolutionary Trends in Plants, v.1, n.1, p.35-39, 1987.

SCHLICHTING, C.D.; STEPHENSON, A.G.; SMALL, L.E. Pollen load and progeny vigor in Cucurbita pepo: the next generation. Evolution, v.44, n.5, p.1358-1372, 1990.

STEPHENSON, A.G.; DEVLIN, B.; HORTON, J.B. The effects of seed number and prior fruit dominance on the pattern of fruit production in Cucurbita pepo (zucchini squash). Annals of Botany, v.62, n.6, p.653-661, 1988.

VIEIRA, R.D., CARVALHO, N.M. Teste de vigor em sementes. Jaboticabal: FCAV/FUNEP, 1994. $164 \mathrm{p}$. 